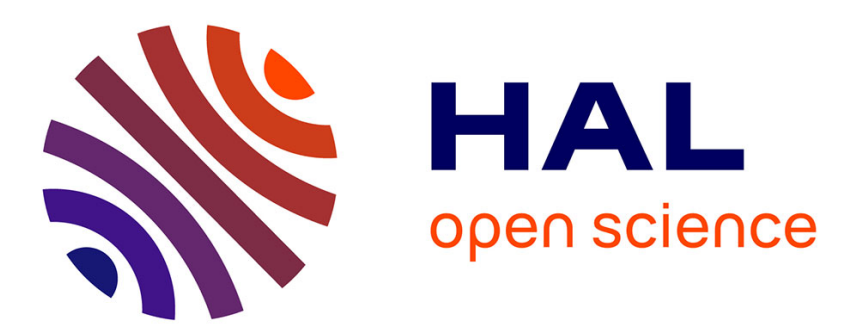

\title{
A comparative frame for a contextualised analysis of local natural risk management \\ Raquel Bertoldo
}

\section{To cite this version:}

Raquel Bertoldo. A comparative frame for a contextualised analysis of local natural risk management. International Journal of Disaster Risk Reduction, inPress, pp.101945. 10.1016/j.ijdrr.2020.101945 . hal-03015837

\section{HAL Id: hal-03015837 https://hal.science/hal-03015837}

Submitted on 20 Nov 2020

HAL is a multi-disciplinary open access archive for the deposit and dissemination of scientific research documents, whether they are published or not. The documents may come from teaching and research institutions in France or abroad, or from public or private research centers.
L'archive ouverte pluridisciplinaire HAL, est destinée au dépôt et à la diffusion de documents scientifiques de niveau recherche, publiés ou non, émanant des établissements d'enseignement et de recherche français ou étrangers, des laboratoires publics ou privés. 
A comparative frame for a contextualised analysis of local natural risk management

Raquel Bertoldo

Aix Marseille Univ, LPS, Aix-en-Provence, France

\section{Acknowledgements}

This project (2016-2019) was funded by the Labex OT-Med (ANR-11- LABEX-0061), supported by the Investissements d'Avenir, French Government project of the French National Research Agency (ANR) through the A*Midex project (ANR-11-IDEX-0001-02). I also thank Claire Mays for carefully reviewing a first version of this manuscript.

Corresponding author:

Raquel Bertoldo. Laboratoire de Psychologie Sociale (UR 879), Aix-Marseille Université, 29 Avenue R. Schuman, 13621 Aix-en-Provence, France. Email: raquel.bohn-bertoldo@univamu.fr. 


\begin{abstract}
Modern natural risk management presupposes that once natural risks are understood, the necessary measures will be taken by the locally competent bodies. Field observations however show that scientific knowledge encounters locally other sources of environmental knowledge which can present resistance to risk management propositions. This special issue adopted a constructivist frame to analyse how natural risks (coastal floods and earthquakes) are locally understood, remembered, and avoided. The comparative fieldwork approach across national contexts (Italy, France and Morocco) in which different natural risks were considered revealed similar local psychosocial dynamics which may be summarised as follows: (1) Knowledge diversity; (2) Local history and trust; (3) Shifting risk rationalisations and (4) Risk objectification.
\end{abstract}




\footnotetext{
"The environment is an instrument of hybridisation that questions old dichotomies: nature and culture, local and national, particular and general, vernacular and scientific knowledge" (ClaeysMekdade \& Allard, 2007, p. 51).
}

Over the course of their local history, Mediterranean communities have learned to adapt to their local environments. Their local knowledge has greatly contributed to the success of their long implantation (Nazarea, 2006). This is why efforts to understand human societies' adaptation to natural risks have underlined the need to understand how risk adaptation and preparedness make sense contextually (Joffe, Rossetto, \& Solberg, 2013; Luís, Vauclair, \& Lima, 2018; Solberg, Rossetto, \& Joffe, 2010). On the other hand, modern risk management agencies are bound to propose risk management policies that are also technically and scientifically sound. The institutions from which natural risk management emanates propose understandings of risks that are generalized and must be 'translated' to a given context (Castro \& Mouro, 2011) where risk preparedness might already exist. Risk management can be in this sense at odds with local cultures that "incessantly problematise their own relationships with expertise of all kinds, as part of their negotiation of their own identities" (Wynne, 1996, p. 50).

The coexistence and cooperation between social groups around the same localities, and the differences between how these entities understand and respond to threats (Breakwell, 2020) illustrate how natural risk management is reinforced when it accounts for the diversity of actors, local histories and identities. We propose in this special issue to analyse how psychosocial processes involved in natural risk knowledge contribute to reinforcing - or to undermining community resilience. More precisely the analyses presented here explore (1) how scientific arguments about natural risks are understood locally and (2) how this knowledge contributes (or not) to building natural risk adaptation strategies. The articles taken together analyse both 
how different types of natural risks - in particular coastal floods and earthquakes - are contextually understood and how this local knowledge influences collective vulnerability around the Mediterranean basin (France, Italy and Morocco).

Throughout the studies presented in this special issue the question "who learns with whom' was posed often with different intentions. Across the generations local inhabitants have learned to understand the intricate behaviour of their surrounding environment; while specialists (scientists, technicians) may dispose of generalised, longitudinal data, risk prevention and mitigation solutions. Any mismatch between specialist logics and their local appropriation for risk preparedness was seen to contribute to the vulnerability of local populations to natural risks (Solberg et al., 2010). In this sense a coordinated contextualised set of analyses would help to enlighten how science-society relations support or hamper natural risk management (earthquakes, marine submersions, landslides, erosion, floods, etc.) around the Mediterranean.

This special issue presents the results of different field investigations in localities where catastrophic natural events are anticipated to take place, but where risk management or local adaptation could - from the specialist's perspective - be improved. The RiskMed ${ }^{1}$ project took an interdisciplinary approach to analysing collective intelligence around naturally observed local risk management. Scientists of different disciplinary perspectives contributed to the study of commonalities and differences in knowledge construction and processes seen in communities around the Mediterranean that are exposed to natural risks (earthquakes, coastal floods, landslides, erosion).

Comparisons of how these different Mediterranean communities use knowledge to adapt to natural risks soon identified common psychosocial factors or processes that impact their

\footnotetext{
${ }^{1}$ This project was funded by the Labex OT-Med (ANR-11- LABEX-0061), supported by the Investissements d'Avenir, French Gov- ernment project of the French National Research Agency (ANR) through the A*Midex project (ANR-11-IDEX-0001-02).
} 
adaptation potential. These are presented below and can be summarised as: (1) Knowledge diversity (2) Local history and trust; and (3) Shifting risk rationalisations and (4) Risk objectification. Certain of these points were part of the upstream analytical frame with which we approached the fieldwork, while others emerged from the data and from their comparison. Each of these points will be illustrated with concrete elements from different fieldwork.

\section{Knowledge diversity: Scientific and 'other' knowledge}

Adaptation to natural risks has been a matter of tradition for generations. The rapid urbanisation of Mediterranean communities created several vulnerabilities that were absent in traditional land management. Since the 1990s European member states have relied on common strategies to direct the management of natural risks at local level - European Water Framework Directive (2000) and, more recently, the Floods Directive (2007). These common strategies raise the question of how these technical or scientific approaches to one's local environment are adapted and understood by communities that used to manage risks on their own (Wynne, 2008).

The conversation between different sources of knowledge is of particular interest to social representations theory (SRT) (Moscovici, 1961/1976, 2001). This theory of social knowledge describes the process by which knowledge emanating from scientific (formalised, reified) spheres becomes invested with 'new' meanings by different social groups. When these new knowledges become familiar in a consensual sphere, it then becomes part of common sense (Moscovici 1961, 2001). This diffusion process involves sharing new information and, with it, new meanings (Joffe, 2003): laypeople resort to metaphors and images to translate these novel ideas into familiar ones (Wagner \& Hayes, 2005).

The symbolism implicit in shared and mediated meaning is part of the reason why SRT can provide a more refined response to the needs of risk communicators. 'Risk perception' 
approaches have constituted the mainstream research in risk analysis (Breakwell, 2014) by raising awareness to the logics over which the lay public rely on to judge different types of risks: from everyday life, health, natural or catastrophic risks (Slovic, 2000). The focus of this approach on individual level cognitive processes left a less theorized aspect of risk perception: how they are based in collective level meaning structures, representations. Constructivist approaches such as the SRT have proposed theoretical frames capable of explaining interindividual systematic risk perception differences through cultural or symbolic differences. These approaches are more "concerned with symbols, social reality and social knowledge" (Joffe, 2003, p.60). As a constructivist theory, SRT understands social knowledge as symbolic. Meaning mediates shared realities, which gains their status as reality by being recognised as socially shared (Raudsepp, 2005). Because the sharedness of a representation within social groups greatly contributes to its reality status, the biding force of social groups or the social identity is pivotal to how shared meanings are organised, and how these meanings can also play an identity protective role (Breakwell, 2001).

Since for SRT all knowledge is relative and context-bound (Moscovici, 2001), it considers scientific knowledge also to be a source of social knowledge. Here an important distinction is warranted between "science as research, scientific knowledge-culture, and science as aspirant public authority knowledge” (Wynne, 2008. p. 24). Scientific institutions are - like publics - reflexive institutions often positioned in relation to policymaking closer to 'science in the making' (Latour \& Woolgar, 1979) in the quest for answers to new and still ill-identified problems for which the context plays a fundamental role (Patterson \& Williams, 2006). The realisation of this fact is crucial in interdisciplinary research: the more colleagues from different disciplines approach risk management as societal issues for which lay publics have past experiences and share valid knowledge, the more resilient and adaptable our adaptation responses will be. 


\section{Local history and trust}

Risk experiences are described in the literature as important predictors of protective behaviour (Gruev-Vintila \& Rouquette, 2007; Lo \& Cheung, 2015) and knowledge (Luís et al., 2018). For this reason, the studies presented here identify direct or indirect (collective history) experiences as paramount elements to understand how local communities consider themselves vulnerable to a risk. These experiences include memories about how local authorities have managed risks in the past, which may also lead to an increase (or decrease) in perceived vulnerability.

Participants interviewed on the southern coast of France (Bertoldo et al., this issue) described their risk experience through personal temporal landmarks (e.g. 'that was the year my daughter was born'; 'my mother was still living'). Environmental experiences are intertwined with personal histories in a place (e.g. Bertoldo et al, this issue). For example, people who have lived their whole life in Port-Saint-Louis-du-Rhône (PSLR) are able to describe exactly what the meteorological conditions should be for the Rhône river to attain its maximum level. Simultaneous high risk awareness and deep place attachment has been described as a paradox (Meur-Ferec \& Guillou, 2020). Our comparative study between two communities with different coastal risk cultures (PSLR and Fréjus) found that PSLR inhabitants, who share a strong place attachment, also demonstrate a deep understanding of how their environment works and how dangerous it can be (Bertoldo et al., this issue). On the other hand, inhabitants of Fréjus - a popular Côte d'Azur retirement destination - have a limited and recent first-hand experience with their surrounding environment. Not only are these participants less aware of the natural risks to which they are exposed, but they also share fewer memories and talk about their environment in less emotional terms. These observations can illustrate the 
ambivalent relationship found in the literature between place attachment and risk perception (Bonaiuto, Alves, De Dominicis, \& Petruccelli, 2016).

Shared local history has also been observed to be a central indicator of how existing natural risks have been managed previously and who can be trusted with managing them (Brondi et al., this issue). Our comparative fieldwork has allowed us to illustrate the strong trust of French local inhabitants in state-run risk management bodies (c.f. Gilli, Velez, Bueso, \& Réaud, 2020). In contrast, Italian participants exposed to earthquakes are more directly critical of their local administrations, in relation to whom they display fatalism and powerlessness in face of management problems they consider overwhelming (Brondi et al., this issue).

French participants in the studies presented here show general support to state and local risk management despite locally active and critical associative networks. Interestingly, the type of criticism local associations address to state-run environmental bodies (see Bertoldo et al., this issue) is formulated in the same highly technical terms as are used by these agencies. The resort to a hermetic technical language has historically contributed to 'dissuade' local communities from engaging in risk management decisions that concern them directly and to which they otherwise would be able to contribute (Claeys-Mekdade \& Allard, 2007). The French tradition of centralized state management of national infrastructure through the Corps des Ponts et Chaussées ["Bridges and Roads Body"] dates back to 1740; it was reinforced in the Napoleonic era with the task of "carrying out all major planning and development projects, roads, railway lines, canals, drainage of wet areas (after the 1807 Act), river embankments, irrigation canals and water supply to towns" (Claeys-Mekdade \& Allard, 2007, p. 42). This approach to environmental management has been greatly questioned because of its expansionist approach treating nature as a 'resource'. Because of the complex dynamics of how climate change disrupts global and local environments, inflexible top-down territorial management might limit the potential of our territories to find climate change adaptation solutions. Highly 
structured and powerful techno-scientific organisations continuously reproduce the same power relations and imbalances between national and local, specialist and vernacular (ClaeysMekdade \& Allard, 2007).

The studies presented in this issue suggest that different types of trust seem to be at play in the case of French or Italian natural risk management (Brondi, et al., this issue). More precisely, considering that 'trust' might be expressed through two complementary dimensions (Bertoldo et al., 2020), one might observe a 'relational' trust - hot or social type of trust that is resilient to inconsistent information; and a 'calculative' trust - cold and cognitive (Engdahl \& Lidskog, 2014). Here, participants from PSLR apparently make use of a calculative trust when they refer to local authorities' 'technical' competence for managing coastal floods, something they have already done in the past (Bertoldo et al., 2020; Bertoldo, this issue). By contrast, Italian participants argue on the basis of a relational type of trust how sceptical they are about local earthquake management (Bertoldo et al., 2020). These results illustrate how communities understand their vulnerability to natural risks, the responsibility of local authorities and how these elements are combined to contribute to a local identity sense of continuity (Breakwell, 2001, 2014). In the next section we will discuss examples of how these socially shared meanings are present in individuals' discursive strategies.

\section{Shifting' rationalisations}

Faced with the fear caused by our exposure to a risk, we can adopt different action strategies: either acknowledge this risk's existence - discuss it and describe how we would adapt to it; or adopt the opposed strategy of risk rationalization and willingly downplay its existence as part of an identity protective strategy (Breakwell, 2001, 2014). In this latter case, our effort could be directed towards justifying a lack of action: either because the risk could be 
seen as too small to warrant action, or too overwhelming for action to make a difference, or too removed in the future for it to be considered our own concern.

In the course of the studies described in this special issue we have seen both strategies acknowledgement and rationalisation - being used, sometimes by the same individual at different moments of the interview (Bertoldo et al., this issue). Here the risk rationalisations could be designated as: social comparison (e.g. 'we are not as exposed as they are'); risk comparison ('what about this other, more important, risk?') and fatalism ('it is all so overwhelmingly bad, what can we do?'). Rationalisations were often used when the individuals expressed little concern for local coastal risks, or when they did little to reduce their exposure despite acknowledging the natural risk.

Such rationalizations of risk exposure have been widely described in risk analytic research (e.g. Luís et al., 2016; Joffe, 2003) as part of individual or collective processes. Breakwell (2001) proposes that these rationalisations become part of social representations and that these representations also contain information about which groups can be trusted or not (Breakwell, 2020), as part of identity defensive strategies. What is interesting in the rationalisations identified in the studies presented in Bertoldo et al. (this issue) is that their main objective seems to be to justify individual inaction in the face of natural risks while local authorities and the state are taken to be responsible for their protection.

These shifting rationalisations rely on inconsistent and sometimes antagonistic arguments, demonstrating how social representations can support communicative acts as if they were 'tools' addressing different needs at different places and times (Raudsepp, 2005). In this sense Joffe et al. (2013) describes the profound differences in how Americans, Turkish and Japanese people regard their responsibility for earthquake preparedness: Americans are more inclined to regard individuals as primarily responsible, whereas at the other extreme Japanese see the state as responsible for household seismic protection. As cultural resources, these risk 
representations are used to address different contextual needs, serving for example as a personal reassurance or to project the blame onto local authorities for not doing enough to manage a community's risk exposure.

\section{Risk objectification}

Scientific knowledge about natural risks has evolved in the understanding of natural phenomena that are generalisable across contexts, times and places (Beck, 1992). Still, societies have repeatedly demonstrated their difficulty to act in the face of abstract, distant (Spence, Poortinga, \& Pidgeon, 2011; Trope \& Liberman, 2003) or never-before-experienced phenomena such as climate change (e.g Marshall, 2014).

Previous psychosocial analysis has illustrated how when faced with real direct (Sarrica et al., 2018) or indirect (Smith \& Joffe, 2009) consequences of natural events, social groups find in shared images a support to exchange about previously abstract ideas. When coupled with images and shared emotions, catastrophic events can galvanise ideas about how a natural risk is thought, remembered, recognised and communicated.

The studies presented in this special issue have also shown how past experience sets important precedent for how the risk of a natural event is imagined and thought possible (Bertoldo et al., this issue; Brondi et al., this issue). Interviews showed how past risk events are often used as a basis to discuss present and future exposure. More precisely, local communities were able to acknowledge the existence of natural risk when they were able to 'see' it, imagine and therefore communicate about it. In the absence of a past risk event providing a concrete representational basis, these events were easily rationalised as distant possibilities that did not affect them directly.

This difficulty of communities or societies to prepare for natural risks that are anticipated by experts but that are - still - absent from the collective memory is here interpreted as a 
limitation in how objectifiable a representation is. Anchoring and objectification are the psychosocial processes Moscovici (1961/1976) uses to explain the emergence of new representations. These two processes are complementary in their use of shared memories to comprehend new events or threats. By anchoring new phenomena in old ones, groups use already existing categories as basis to understand newer, not yet familiar ones. This process explains the resort to approximations with past natural events, metaphors and the like when groups are confronted with unfamiliar objects. Objectification on the other hand is what renders these shared memories accessible on the first place. When abstract ideas or representations are objectified, they acquire materiality and "become expressions of a reality thought as natural" (Vala, 2000, p. 465, our translation). When representations are materialized, they become an icon that summarises quickly and intuitively an idea that become easily communicated and remembered.

Objectification describes therefore a paramount process for how risks are represented and come to assume a "concrete shape" (Moscovici, 1989) through risk management institutions. When a risk fails to be objectified, we can consider this risk to be yet in a state of 'latency', where it possibility exists as a certitude for some individuals or groups, but not for society's shared scheme of reality. Based on observations presented in this special issue we propose that ill-objectified risks remain in an epistemic state that is typical of socially attenuated risks (Kasperson et al., 1988). The collective experience of a natural catastrophe can surely contribute to the objectification of a risk, but as described elsewhere (Poumadère et al., 2005) the amplification of a risk, and its objectification, depends on how an event unfolds in relation to a context shaped by risk management institutions, policymakers and individuals, all of these nested in a culture. For this reason, we consider the objectification of a risk as part of the representational process in the absence of which an idea (or representation) is doomed to be forgotten (Moscovici, 1988). 
In the understanding of our participants, unless 'something happens' in relation to coastal floods in southern France (Bertoldo et al., this issue), policymakers have little incentive to invest in avoiding them, even in the face of scientific advice. In this manner, unless a threat is remembered, objectified in the shared symbolic tissue, it would also fail to leverage popular mobilisation and state response.

\section{Special issue articles}

The articles included in this special issue mirror in different ways the need to apprehend risk management contextually in order to understand societal response. The articles that compose this special issue frame the local knowledge in different ways and propose different pictures of how publics organise local scientific issues. Our shared approach to local understandings of natural risks is not one that proposes this source of knowledge as being 'better' than scientific views (see Wynne, 2008) but rather focuses on local "multiple knowledges, reflecting their different sets of priority concerns [...], accountably validated as far as possible, and if necessary (but unity or consensus should not be presumed) negotiated together as such" (Wynne, 2008, p. 28).

The article by Bertoldo, Guignard, Dias and Schleyer-Lindenmann describes a comparative study of two localities at risk for coastal floods. Qualitative analysis was able to show how the two places studied (Port-Saint-Louis-du-Rhône and Fréjus) involve different types of community ties to the environment and consequently different ideas of what local issues are (Wynne, 2008).

The article by Brondi, Benedetti, Tanga and Bertoldo (this issue) describes a comparative study between two localities of the Italian Apennine region with different recent earthquake experiences. Based on different environmental cues in their local environment these two localities prioritize earthquake risks differently as a function of their recent seismic experience. 
Ivcevic and collaborators (this issue) take us to the southern Mediterranean coast where the northern Morocco region of Tangier-Tetouan-Al Hoceima can be characterised as a multirisk zone (floods and earthquakes). The article analyses how different variables explain residents' willingness to protect themselves and to invest financially in their protection from natural risks. The study shows that regional differences associated with varied sociodemographic profiles significantly contribute to risk management strategies. Ivcevic, Statzu, Satta and Bertoldo (this issue) also analysed in Sardinia (Italy) local publics' interpretation of wetlands as a protective feature against coastal floods, coupled with an economic analysis of how willing they are to invest in these - often regarded as unpleasant environments.

Our Mediterranean-centered approach to risk management is complemented by invited comparative contributions analysing risk management on different Atlantic coasts: French, Canadian and Colombian. The first of these invited contributions includes the article by Navarro and colleagues (this issue) which presents a study interested in the adoption of protective behaviours regarding erosion and coastal flooding risks in the French Atlantic coast. They use qualitative and regression modelling to identify the variables explaining the adoption of coastal flood protective behaviour.

Mocaer, Guillou et Chouinard (this issue) compare the ‘systemic vulnerability' of atlantic coast dwellers in France and Canada to erosion and floodig risks. This comparative analysis considered how different people-place variables (e.g. place attachment, dependance, social identity, coastal risk experience) contribute to reinforce the resilience of these two communities. This analysis also proposes a dialogue between the theory of social representaitons and the concept of systemic vulnerabilities. 
Also in the Atlantic, Duque-Muñoz, Navarro, Restrepo and Fleury-Bahi (this issue) bring us to the Caribean to explore how Cartagena (Colombia) inhabitants understand and protect themselves from coastal flood hazards.

Our last invited article by Guillard, Navarro and Fleury-Bahi (this issue) presents an analysis of how psychological distance and place attachment predict risk perception and the adoption of climate change adaptation measures across groups of Colombian participants who had experienced floods or droughts.

\section{Conclusion}

This special issue was proposed with a common assumption of how natural risks are understood locally. Contributors made use of widely different methodological approaches structural equation modelling, qualitative analysis or econometry. Still they shared a common view about how natural risks acquire the thick reality conveyed by through being socially shared.

These international comparisons across nations, cities, social groups and risks have contributed very contextualized descriptions of how local natural risks are based on social memories. Despite their differences, they also revealed similar dynamics in locally embedded processes involving knowledge status, institutional trust, experience, rationalisation or risk objectification.

Taken together, the synthesis presented above illustrates the role of socially constructed realities (Joffe, 2003) engrained in Disaster Risk Reduction. Shared memories, social knowledge, and symbols are enacted through social relations and communications that might explain why risk management strategies succeed or fail.

\section{Special issue references}


Bertoldo, R. Guignard, S. Dias P. \& Schleyer-Lindenmann, A. (this issue). Coastal inconsistencies: An analysis of how coastal flood risk is understood and anticipated in southern France. International Journal of Disaster Risk Reduction, 50.

Brondi, S., Benedetti, L., Tanga, R. C., \& Bertoldo, R. (this issue). Between oblivion and drastic evidence: How local communities cope with seismic risk by forgetting and remembering. International Journal of Disaster Risk Reduction, 50.

Duque-Muñoz, L. A., Navarro, O., Restrepo, Fleury-Bahi. G. (this issue). Assessment and management of risk in inhabitants exposed to coastal flooding risks: The case of Cartagena, Colombia. International Journal of Disaster Risk Reduction, 50.

Guillard, M., Navarro, O., \& Fleury-Bahi, G. (this issue). How do we adapt when we are faced with the effects of climate change? International Journal of Disaster Risk Reduction, 50.

Ivcevic, A., Bertoldo, R., Mazurek, H., Siame, L., Guignard, S., Ben Moussa, A., \& Bellier, O. (2020). Local risk awareness and precautionary behaviour in a multi-hazard region of North Morocco. International Journal of Disaster Risk Reduction, 50. https://doi.org/10.1016/j.ijdrr.2020.101724

Ivcevic, A., Statzu, V., Satta, A., \& Bertoldo, R. (this issue). The future protection from the climate change-related hazards and the willingness to pay for home insurance in the coastal wetlands of West Sardinia, Italy. International Journal of Disaster Risk Reduction, 50.

Mocaer, A., Guillou, E., \& Chouinard, O. (this issue) The social construction of risk: A study of coastal risks (erosion and flooding) in France and Canada. International Journal of Disaster Risk Reduction, 50.

Navarro, O., Mambet, C., Barbaras, C., Chadenas, C., Robin, M., Chotard, M., Desvergne, L., Desse, M., Chauveau, E. \& Fleury-Bahi, G. (this issue). Determinant factors of protective behaviors regarding erosion and coastal flooding risk. International Journal of Disaster Risk Reduction, 50.

\section{Acknowledgements}

This work is a contribution to Labex OT-Med ( ${ }^{\circ}$ ANR-11-LABX-0061) and received funding from Excellence Initiative of Aix-Marseille University-A*MIDEX, a French “Investissements d'Avenir" programme (RISKMED project). Additional funding was provided for the study in France by the European Union-FEDER programme (DIGUE 2020 project). I also like to thank Claire Mays for carefully reviweing a first version of this manuscript. 


\section{References}

Beck, U. (1992). Risk society: Towards a new modernity. Sage.

Bertoldo, R., Tanga, R., Dias, P., Guignard, S., \& Schleyer-Lindenmann, A. (2020).

Calculative and relational trust in the management of coastal floods and earthquakes: A comparative study. PsyEcology, 11(2), 193-213.

https://doi.org/10.1080/21711976.2020.1734398

Bonaiuto, M., Alves, S., De Dominicis, S., \& Petruccelli, I. (2016). Place attachment and natural environmental risk: Research review and agenda. Journal of Environmental Psychology, 48(2016), 33-53. https://doi.org/10.1016/j.jenvp.2016.07.007

Breakwell, G. (2014). Identiy process theory: Clarifications and elaborations. In.: R. Jaspal \& G. Breakwell (Eds.), Identity process theory: Identity, social action and social change (pp. 20-37). Cambridge University Press.

Breakwell, G. M. (2001). Mental models and social representations of hazards: The significance of identity processes. Journal of Risk Research, 4(4), 341-351. https://doi.org/10.1080/1366987011006273

Breakwell, G. M. (2020). Mistrust, uncertainty and health risks. Contemporary Social Science, O(0), 1-13. https://doi.org/10.1080/21582041.2020.1804070

Castro, P., \& Mouro, C. (2011). Psycho-Social processes in dealing with legal innovation in the community: Insights from biodiversity conservation. American Journal of Community Psychology, 47(3-4), 362-373. https://doi.org/10.1007/s10464-010-9391-0

Claeys-Mekdade, C., \& Allard, P. (2007). Managing the environment and metamorphoses of the State: the French experience. Desenvolvimento e Meio Ambiente, 16, 39-53.

Engdahl, E., \& Lidskog, R. (2014). Risk, communication and trust: Towards an emotional understanding of trust. Public Understanding of Science, 23(6), $703-717$. https://doi.org/10.1177/0963662512460953

Gilli, L. Velez, R. Bueso, P. \& Réaud, C. (2020). Baromètre 2020: La perception des risques et de la sécurité par les français [Barometer 2020: The perception of risks and safety by the French]. IRSN. Available at: https://www.irsn.fr/FR/IRSN/Publications/barometre

Gruev-Vintila, A., \& Rouquette, M. (2007). Social thinking about collective risk: How do risk-related practice and personal involvement impact its social representations? Journal of Risk Research, 10(4), 555-581. https://doi.org/10.1080/13669870701338064

Joffe, H. (2003). Risk: From perception to social representation. British Journal of Social Psychology, 42, 55-73.

Joffe, H., Rossetto, T., \& Solberg, C. (2013). Social representations of earthquakes: A Study of people living in three highly seismic areas. Earthquake Spectra, 29(2), 367-397. https://doi.org/10.1193/1.4000138 
Kasperson, R. E., Renn, O., Slovic, P., Brown, H. S., Emel, J., Goble, R., ... Ratick, S.

(1988). The Social Amplification of Risk: A conceptual framework. Risk Analysis, 8(2), $177-187$.

Latour, B. \& Woolgar, S. (1979). Laboratory life: The social construction of scientific facts. Sage.

Lo, A. Y., \& Cheung, L. T. O. (2015). Seismic risk perception in the aftermath of Wenchuan earthquakes in southwestern China. Natural Hazards, 78(3), 1979-1996. https://doi.org/10.1007/s11069-015-1815-6

Luís, S., Pinho, L., Lima, M. L., Roseta-Palma, C., Martins, F. C., \& Betâmio de Almeida, A. (2016). Is it all about awareness? The normalization of coastal risk. Journal of Risk Research, 19(6), 810-826. https://doi.org/10.1080/13669877.2015.1042507

Luís, S., Vauclair, C., \& Lima, M. L. (2018). Raising awareness of climate change causes? Cross-national evidence for the normalization of societal risk perception of climate change. Environmental Science and Policy, 80(November 2017), 74-81. https://doi.org/10.1016/j.envsci.2017.11.015

Marshall, G. (2014). Don't even think about it: Why our brains are wired to ignore climate change? Bloomsbury.

Meur-Ferec, C., \& Guillou, E. (2020). Interest of social representations theory to grasp coastal vulnerability and to enhance coastal risk management. PsyEcology, 11(1), 78-89. https://doi.org/10.1080/21711976.2019.1644003

Moscovici, S. (1961/1976). La psychanalyse, son image et son public. Presses Universitaires de France.

Moscovici, S. (1988). Notes towards a description of social representations. European Journal of Social Psychology, 18, 211-50.

Moscovici, S. (1989). Preconditions for explanation in social psychology. European Journal of Social Psychology, 19, 407-430.

Moscovici, S. (2001). Why a theory of social representations? In K. Deaux \& G. Philogène (Eds.), Representations of the social (pp. 8-35). Oxford: Blackwell.

Nazarea, V. D. (2006). Local Knowledge and memory in biodiversity conservation. Annual Review of Anthropology, 35, 317-35.

https://doi.org/10.1146/annurev.anthro.35.081705.123252

Patterson, M. E., \& Williams, D. R. (2006). Maintaining research traditions on place:

Diversity of thought and scientific progress. Journal of Environmental Psychology, 25(2005), 361-380. https://doi.org/10.1016/j.jenvp.2005.10.001

Poumadère, M., Mays, C., Le Mer, S., \& Blong, R. (2005). The 2003 heat wave in France: Dangerous climate change here and now. Risk Analysis, 25(6), 1483-1494. https://doi.org/10.1111/j.1539-6924.2005.00694.x 
Raudsepp, M. (2005). Why is it so difficult to understand the theory of social representations? Culture and Psychology, 11(4), 455-468. https://doi.org/10.1177/1354067X05058587

Rijsman, J., \& Stroebe, W. (1989). Introduction: The two social psychologies or whatever happened to the crisis? European Journal of Social Psychology, 19, 339-344.

Sarrica, M., Farinosi, M., Comunello, F., Brondi, S., Parisi, L., \& Fortunati, L. (2018). Shaken and stirred: Social representations, social media, and community empowerment in emergency contexts. Semiotica, 2018(222), 321-346. https://doi.org/10.1515/sem-20160208

Slovic, P. (2000). The Perception of Risk. Earthscan.

Smith, N. W., \& Joffe, H. (2009). Climate change in the British press: the role of the visual. Journal of Risk Research, 12(5), 647-663. https://doi.org/10.1080/13669870802586512

Solberg, C., Rossetto, T., \& Joffe, H. (2010). The social psychology of seismic hazard adjustment : re-evaluating the international literature. Natural Hazards and Earth Sciences, 10, 1663-1677. https://doi.org/10.5194/nhess-10-1663-2010

Spence, A., Poortinga, W., \& Pidgeon, N. (2012). The psychological distance of climate change. Risk Analysis, 32(6), 957-972. https://doi.org/10.1111/j.15396924.2011.01695.x

Trope, Y., \& Liberman, N. (2003). Temporal construal. Psychological Review, 110(3), 403421. https://doi.org/10.1037/0033-295X.110.3.403

Vala (2000). Representações sociais e psicologia social do conhecimento quotidiano [Social representations and social psychology of everyday knowledge]. In: J. Vala \& M. B. Monteiro (Eds.), Psicologia social (4th rev. ed., pp. 457-502). Fundação Calouste Gulbenkian.

Wagner, W., \& Hayes, N. (2005). Everyday discourse and common-sense: The theory of social representations. Palgrave Macmillan.

Wynne, B. (1996). May the sheep safely graze? A reflexive view of the expert-lay knowledge divide. In S. Lash, B. Szerszynski, \& B. Wynne (Eds.), Risk Environment and Modernity: Towards a New Ecology (pp. 44-83). Sage.

Wynne, B. (2008). Elephants in the rooms where publics encounter "science"?: A response to Darrin Durant, "Accounting for expertise: Wynne and the autonomy of the lay public." Public Understanding of Science, 17, 21-33. https://doi.org/10.1177/0963662507085162 